\title{
Influence of Si Coating on Interfacial Microstructure of Laser Joining of Titanium and Aluminium Alloys
}

\author{
Aline Capella de Oliveira ${ }^{a *}$, André Felipe Ribeiro Moreira ${ }^{a}$, Carina Barros Mello ${ }^{b}$, Rudimar Rivac, \\ Rogério de Moraes Oliveira ${ }^{b}$ \\ ${ }^{a}$ Instituto de Ciência e Tecnologia, Universidade Federal de São Paulo, São José dos Campos, SP, Brazil \\ ${ }^{b}$ Instituto Nacional de Pesquisas Espaciais, Av. dos Astronautas, 1.758, Jardim da Granja, São José dos \\ Campos, SP, Brazil \\ 'Instituto de Estudos Avançados, Trevo Coronel Aviador José Alberto Albano do Amarante, 01, Putim, \\ São José dos Campos, SP, Brazil
}

Received: December 20, 2016; Revised: September 01, 2017; Accepted: October 05, 2017

\begin{abstract}
A common phenomenon in the dissimilar joints is the presence of brittle compounds in the joining interface region. The brittle phases can decrease by introduction of interlayers in the joining interface, such as silicon, that inhibits the formation of $\mathrm{Al}_{3} \mathrm{Ti}$ and $\mathrm{AlTi}_{3}$ phases in joining process between titanium and aluminium alloys. In the present work, the joining of titanium and aluminium alloys have been carried out using a $\mathrm{Yb}$ :fiber laser, considering the prior silicon film deposited on titanium alloy interface by DC magnetron sputtering. Butt joint conditions were maintained constant: laser average power, process speed and beam positioning along the interface joining toward aluminium alloy (1200 W, $3.0 \mathrm{~m} / \mathrm{min}$ and $0.3 \mathrm{~mm}$, respectively). Metallographic analyses were carried out on the cross-section joint by optical and electronic microscopies. When the melted aluminium alloy wet the solid-state titanium alloy, a more restrict compound layer was formed in the joining interface. EDS line scanning in the joining interface showed a reduction of compound layer thickness, considering the silicon as interlayer, reaching the mean value of $3 \mu \mathrm{m}$, i.e., up to five times thinner if compared to joining without silicon during the process.
\end{abstract}

Keywords: dissimilar metals, joining process, Ti-6Al-4V, AA6013

\section{Introduction}

The industrial demand for hybrid components has increased the necessity for joining dissimilar metallic materials ${ }^{1,2}$. Different techniques have been used for joining of dissimilar metals such as diffusion welding, brazing, friction stir welding, electron beam welding, and laser welding, 3 . Independently of the process considered, involving liquid or solid states, brittle intermetallic compounds can be formed in the joining interface. These brittle phases degrade the material mechanical properties, promoting the formation of cracks during static or cyclic loads 5 . The joining between titanium and aluminium alloys, for example, generates the $\mathrm{Al}_{3} \mathrm{Ti}$ and $\mathrm{AlTi}_{3}$ intermetallic compounds that decrease the joint quality ${ }^{6}$. Luo and Acoff ${ }^{7}$ analyzed the influence of reaction annealing temperature, time and atmosphere on the multilaminated composites of titanium and aluminium prepared by cold-roll bonding. Their results shown the formation of intermetallic compound $\mathrm{Al}_{3} \mathrm{Ti}$ in relatively short times at low reaction annealing temperatures, $600^{\circ} \mathrm{C}$ and $680^{\circ} \mathrm{C}$. Morizono et al..$^{8}$ also investigated the interfacial reactions in aluminum and titanium solid states, beside liquid aluminum and solid titanium states, using explosive energy. According

*e-mail: alinecapella@gmail.com to the authors, the intermetallic $\mathrm{Al}_{3} \mathrm{Ti}$ was formed along the aluminum and titanium interface in both conditions, being the layer thickness increased with the process holding time. Kimura et al. ${ }^{9}$ also suggested the influence of the friction time in the formation of intermetallic compound layer in friction welded joint between Ti-6Al-4V and Al-Mg alloys. In this case, an intermetallic compound, consisting of $\mathrm{Ti}_{2} \mathrm{Mg}_{3} \mathrm{Al}_{18}$, was observed at welded interface generating fracture of the joint in this region.

In equilibrium conditions, the formation of intermetallic phases may be related to the system phase diagram $\mathrm{s}^{10}$. However, in the non-equilibrium experimental conditions the stability may not be present and knowledge of the parameters related to the formation of intermetallic layers to achieve a stable process is necessary.

In literature, different methods have been applied to inhibit the formation of brittle intermetallic compounds in the joining interface of dissimilar metals ${ }^{1,11}$. Researches concerning the laser joining of titanium and aluminium alloys have shown that the thick intermetallic layer can be restricted only when the titanium alloy melts during the process. The high cooling rate inherent to laser processing decreases the interaction time between the melted aluminium alloy and the solid titanium alloy, promoting thinner intermetallic layers ${ }^{12,13}$. 
The brittle phases can be decreased by introducing of filler metals, or thin sheets, in the joining ${ }^{14,15}$ interface. Chen et al. ${ }^{3}$ have introduced Al-12Si filler metal in the aluminium and titanium interface in the laser joining process. According to the authors, the diffusion of silicon during the process generates other compounds such as $\mathrm{Ti}_{7} \mathrm{Al}_{5} \mathrm{Si}_{12}$ and $\mathrm{Ti}_{5} \mathrm{Si}_{3}$, inhibiting the formation of the $\mathrm{Al}_{3} \mathrm{Ti}$ and $\mathrm{AlTi}_{3}$ phases. The influence of silicon on aluminium and titanium joining interface during the vacuum brazing have been analyzed by Takemoto et al. ${ }^{16}$. The authors observed the formation of multiple phases inhibiting the $\mathrm{Al}_{3} \mathrm{Ti}$ compound, improving the joint mechanical resistance. However, the introduction of filler metals in the interface joining requires suitable fasteners to ensure the thermal contact between the alloys to be joined, especially in the laser process. The main drawback refers to laser energy that is absorbed by material surface and conducted to interface region by thermal conduction, being necessary a good fixation between the dissimilar materials.

Different deposition techniques have been used in process involving titanium substrate to improve its surface characteristics. Researches concerning the silicon deposition as interfacial layer between the alloy and DLC (Diamond Like Carbon) films have been considered to improve the film adhesion to the substrate involved ${ }^{17,18}$. Ti-6Al-4V alloy coated with $\mathrm{SiO}_{2}$ has been considered for biomedical applications such as prostheses or implants ${ }^{19}$. Silicon deposition by DC magnetron sputtering technique has been limited to applications in micro and macro electronics such as insulator substrates and solar cells ${ }^{20}$. Combined DC-RF magnetron sputtering has also been carried out to obtain silicon epitaxy on silicon substrates ${ }^{21}$.

In the present work, the joining between titanium and aluminium alloys have been performed using a $\mathrm{Yb}$ :fiber laser, considering the prior silicon thin film deposited by DC-RF magnetron sputtering in titanium alloy interface. The main goal of this research is to evaluate the influence of the control of laser process parameters and of the introduction of silicon, as filler material in the joining process, in the reduction of intermetallic layer thickness formed in the joining interface between the titanium and aluminium alloys.

\section{Experimental Details}

\subsection{Material and experimental setup}

Sheets of titanium and aluminium alloys, AA6013-T4 and Ti-6Al-4V, with $1.6 \mathrm{~mm}$ and 1.0 thick, respectively, were used. The chemical composition of these sheets is presented in Table 1. All sheets were cut with dimensions of $20 \mathrm{~mm}$ x $25 \mathrm{~mm}$, cleaned with abrasive paper ( $\mathrm{SiC}$ grit 600) and ethanol to remove the residual grease and contaminants.

Prior to the joining process between the dissimilar metals, silicon deposition was carried out on a silicon substrate by magnetron sputtering powered by $300 \mathrm{~V}, 90 \mathrm{mADC}$ and $50 \mathrm{~W}$ RF sources (combined DC-RF) with 0.6 Pa work pressure and argon ambient, for $30 \mathrm{~min}$ to determine the film thickness and the deposition rate of the process. For this, the silicon substrate was partially covered with a mask on its surface, preventing the deposition of the silicon film in this region. Thereafter, the sample was analyzed by using scanning electron microscopy (SEM, JEOL JSM 6701S) to measure the height between deposited film and the measurement substrate.

Considering the same experimental conditions $(300 \mathrm{~V}$, $90 \mathrm{~mA}$ DC and 50 W RF sources with 0.6 Pa work pressure and argon ambient), silicon was deposited on Ti-6Al-4V substrates with deposition time of 1 and 2 hours. In this case, the silicon film was deposited on the longitudinal section of the substrate, to analyze the formation of possible defects of the film, and on its transverse section, to later junction between the dissimilar alloys.

Afterwards, Ti-6Al-4V and AA6013-T4 sheets were joined using a laser joining system. Figure 1 shows the schematic diagrams of the laser joining system (Figure 1a) and the beam positioning along the junction interface toward to aluminium alloy (Figure 1b). Dissimilar metal sheets were tightly champed and fixed on a XYZ CNC moving table. A high-power $Y b$ :fiber laser with a $2 \mathrm{~kW}$ maximum power (IPG, YLS 2000) was used in the experiments. With a lens of 160 $\mathrm{mm}$ focal length, the laser beam was focused on the sample with $100 \mu \mathrm{m}$ estimated diameter ${ }^{22}$. Butt joint conditions were maintained constant and selected from the previous work ${ }^{23}$ based on the influence of the experimental parameters on the formation of joints: laser average power, process speed and beam positioning along the interface joining toward aluminium alloy (1200 W, $3.0 \mathrm{~m} / \mathrm{min}$ and $0.3 \mathrm{~mm}$, respectively). Helium with $20 \mathrm{~L} / \mathrm{min}$ flow rate was used as shielding gas.

\subsection{Microstructure analysis}

The specimens were ground with abrasive paper ( $\mathrm{SiC}$ grits of 240, 400, 600 and 1200, respectively), polished to a mirror finish $\left(1.0 \mu \mathrm{m} \mathrm{Al}_{2} \mathrm{O}_{3}\right.$ solution and colloidal $\left.\mathrm{SiO}_{2}\right)$ and chemically etched using Keller's reagent ( $2 \mathrm{ml}$ of $\mathrm{HF}$, $1 \mathrm{ml}$ of $\mathrm{HNO}_{3}$ and $88 \mathrm{ml}$ of $\mathrm{H}_{2} \mathrm{O}$ ).

Metallographic analyses were carried out on the joint cross-section and the intermetallic layers by optical microscopy (OM, Zeiss AxioImager Z2m) and scanning electron microscopy (SEM, JEOL JSM 6701S) equipped with an energy dispersive X-ray spectrometer (EDS). EDS line scanning evaluated the elemental distribution at the joint interface with and without the introduction of Silicon.

\section{Results and Discussion}

\subsection{Silicon film deposited on the Ti-6Al-4V substrate}

Ti-6Al-4V has coated with silicon by combined DC-RF magnetron sputtering, mainly to evaluate the influence of 
Table 1. Chemical composition of Ti-6Al-4V and AA6013-T4 (\%).

\begin{tabular}{lccccccccc}
\hline Alloys & $\mathrm{Ti}$ & $\mathrm{Al}$ & $\mathrm{V}$ & $\mathrm{Si}$ & $\mathrm{Cu}$ & $\mathrm{Fe}$ & $\mathrm{Mg}$ & $\mathrm{Mn}$ & Others, total \\
\hline Ti-6Al-4V & Balance & $6,80 \pm 0,02$ & $4,36 \pm 0,04$ & $\ldots$ & $0,05 \pm 0,04$ & $0,39 \pm 0,02$ & $\ldots$ & $\ldots$ & $0,08 \pm 0,02$ \\
AA6013-T4 & $\ldots$ & Balance & $\ldots$ & $0,62 \pm 0,02$ & $0,82 \pm 0,02$ & $0,20 \pm 0,02$ & $0,94 \pm 0,05$ & $0,27 \pm 0,04$ & $0,06 \pm 0,01$ \\
\hline
\end{tabular}

(a)

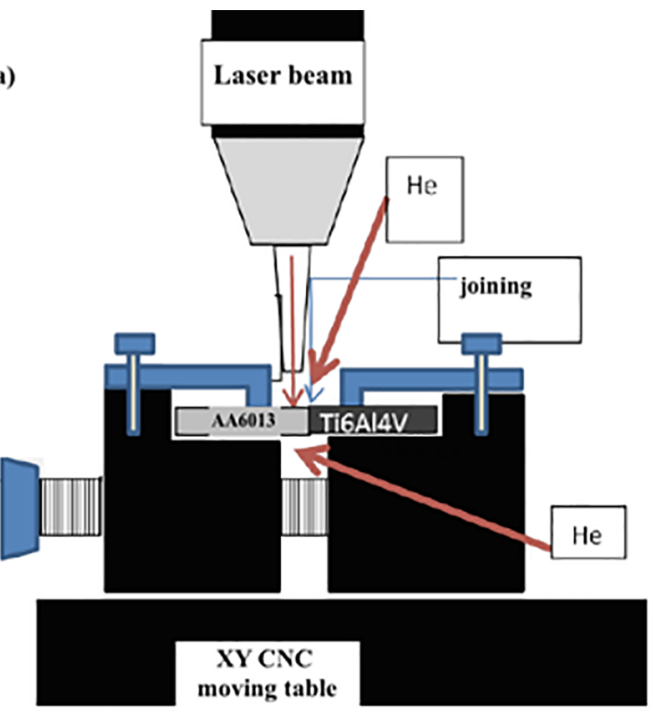

(b)

\section{Yb:fiber laser (Processing head)}
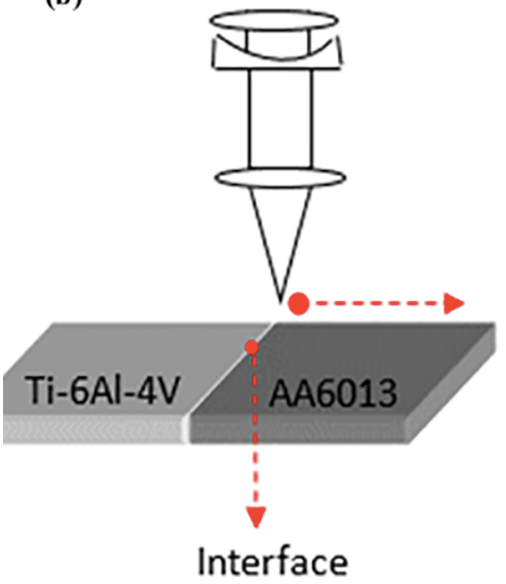

\section{Beam positioning}

Figure 1. Schematic diagram of the joining experiment, showing (a) the laser joining system and (b) the variation of beam positioning along of interface joining toward $\mathrm{Al}$ alloy

silicon on the microstructure of the joining interface between titanium and aluminium alloys.

Figure 2 shows the optical microscopy of silicon film deposited on silicon substrate for $30 \mathrm{~min}$. The height between the film deposited on silicon substrate was measured by SEM, showing a layer with $200 \mathrm{~nm}$ thickness and $7 \mathrm{~nm} /$ min growth rate. Once the silicon layer, deposited on the transverse section of the Ti-6Al-4V, could not be measured, it was estimated that its thickness reached about $400 \mathrm{~nm}$ and $800 \mathrm{~nm}$, considering deposition time of 1 and 2 hours, respectively.

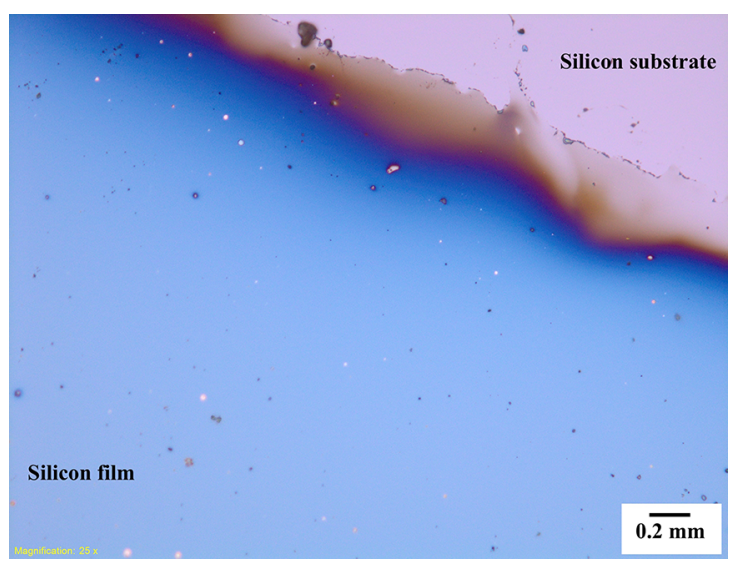

Figure 2. Optical microscopy of silicon film deposited on silicon substrate.

Figure 3 shows the optical microscopy of silicon film deposited on Ti-6Al-4V for 1 hour. Despite of the identification of few defects (holes), a good film adherence on the surface substrate was observed. Moreover, the defects observed in the film may be attributed to high roughness of the substrate surface, associated to scratches present on this region, promoting an irregular film during the deposition process. The film bluish aspect may be attributed to film oxidation due to its exposition to ambient atmosphere after the deposition process.

\subsection{Metallographic characteristics of the dissimilar joints}

The cross-section of aluminium and titanium joints performed using a Yb:fiber laser is presented in Figure 4, considering two laser beam positions (in the interface line

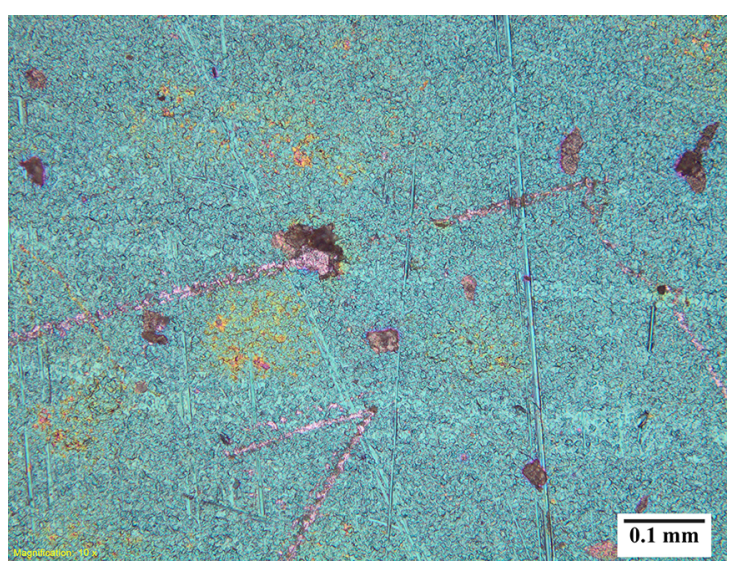

Figure 3. Optical microscopy of silicon film deposited on Ti-6Al$4 \mathrm{~V}$ substrate for 1 hour. 


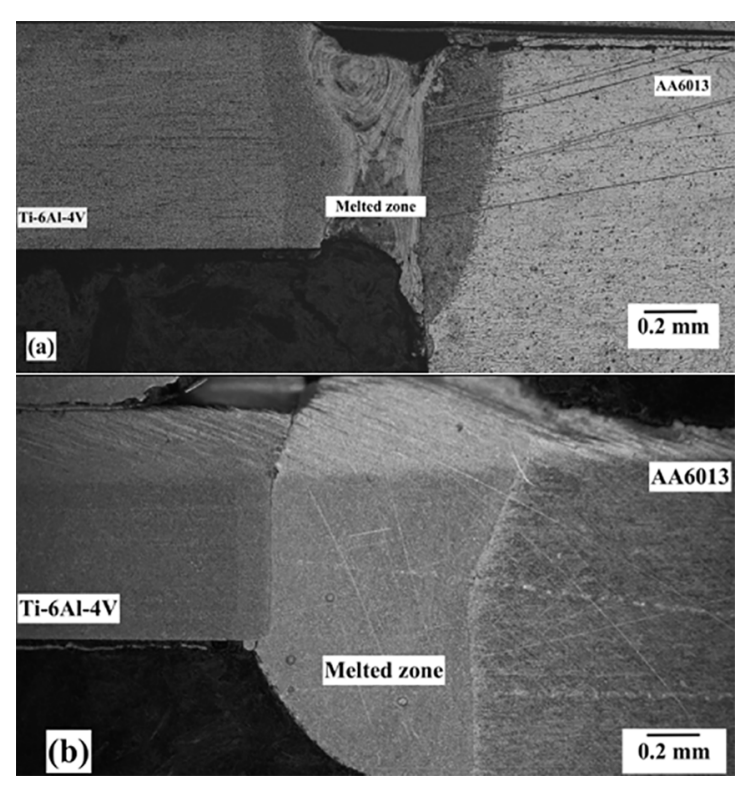

Figure 4. Ti/Al joint cross-sections with different laser positions, (a) interface line and (b) $0.3 \mathrm{~mm}$ toward Al alloy.

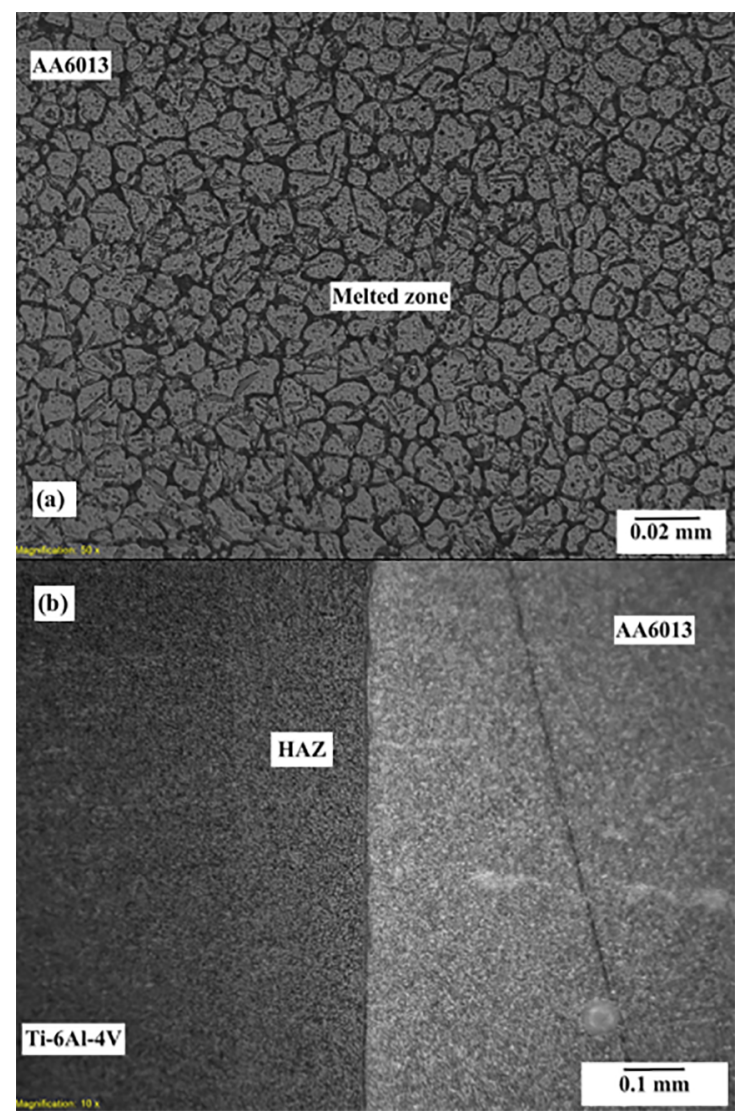

Figure 5. Microstructure of the joint (a) on the side of Al alloy and (b) the heat-affected zone (HAZ) on the side of Ti alloy. and at $0.3 \mathrm{~mm}$ toward aluminium alloy, respectively). With the laser beam positioned in the interface line displaced at $0.3 \mathrm{~mm}$ toward aluminium alloy (Figure 4-b), the titanium alloy did not melt. In this case, the melted aluminium alloy wets the joining interface, triggering the joining of dissimilar metals $^{24}$. The non-fusion of titanium alloy along the process restricts the thickness of brittle phases. On the other hand, when the laser beam was positioned in the interface line (Figure 4-a), both the titanium and aluminium alloy were melted. According to Majumdar et al. ${ }^{11}$, a mixed fusion zone composed of $\mathrm{TiAl}_{3}, \mathrm{TiAl}$ and $\mathrm{Ti}_{3} \mathrm{Al}$ is generated, which deteriorates the mechanical properties of the junction.

Similarly, to the observed in previous work ${ }^{14}$, the fusion zone of aluminium alloy exhibits a fine cellular dendritic solidification structure with many equiaxial grains in the weld centerline (Figure 5-a). Figure 5-b shows the heat-affected zone (HAZ) adjacent to the interface of titanium alloy side. While the titanium alloy has not been melt, with the laser beam was positioned at 0.3 toward aluminium alloy, the thermal cycle of the process modifies the microstructure of the region. Song et al. ${ }^{21}$ have associated these changes to an increase in volume fraction of $\alpha$ phase and a decrease in $\beta$ phase when compared with titanium alloy base metal.

Figure 6 exhibits the interfacial microstructure of three zones of the joint transverse section. The reaction layer can be seen with non-uniform thickness along the transverse section. In previous works ${ }^{1,8}$, this reaction layer has been characterized as zones with club-shaped and cellular/ serration-shaped morphologies.

\subsection{Influence of silicon film on the microstructure of joining interface}

Studies have shown that the formation of brittle phases in the joining interface can be restricted by introducing silicon in this region ${ }^{3,13}$. In the present study, silicon was introduced in joining interface for its deposition on titanium alloy, by means of the magnetron sputtering technique.

Figure 7 presents the transverse section of the joining interface with silicon film on titanium alloy, deposited for 1 and 2 hours (Figures 7-a and 7-b, respectively), comparing with the aluminium and titanium joining without silicon (Figure 7-c). There was a significant variation on compound layer thickness with the introduction of silicon film in this region. Though the distribution of the layer thickness varies along the transverse section (Figure 6) the layer is thinner when compared to one formed in the joining without silicon introduction. This aspect may be associated with a lower diffusion rate of the titanium atoms toward the aluminium alloy, that in solid state are alloyed to the silicon, generating the $\mathrm{Ti}_{5} \mathrm{Si}_{3}$ precipitates and inhibiting the reaction between 


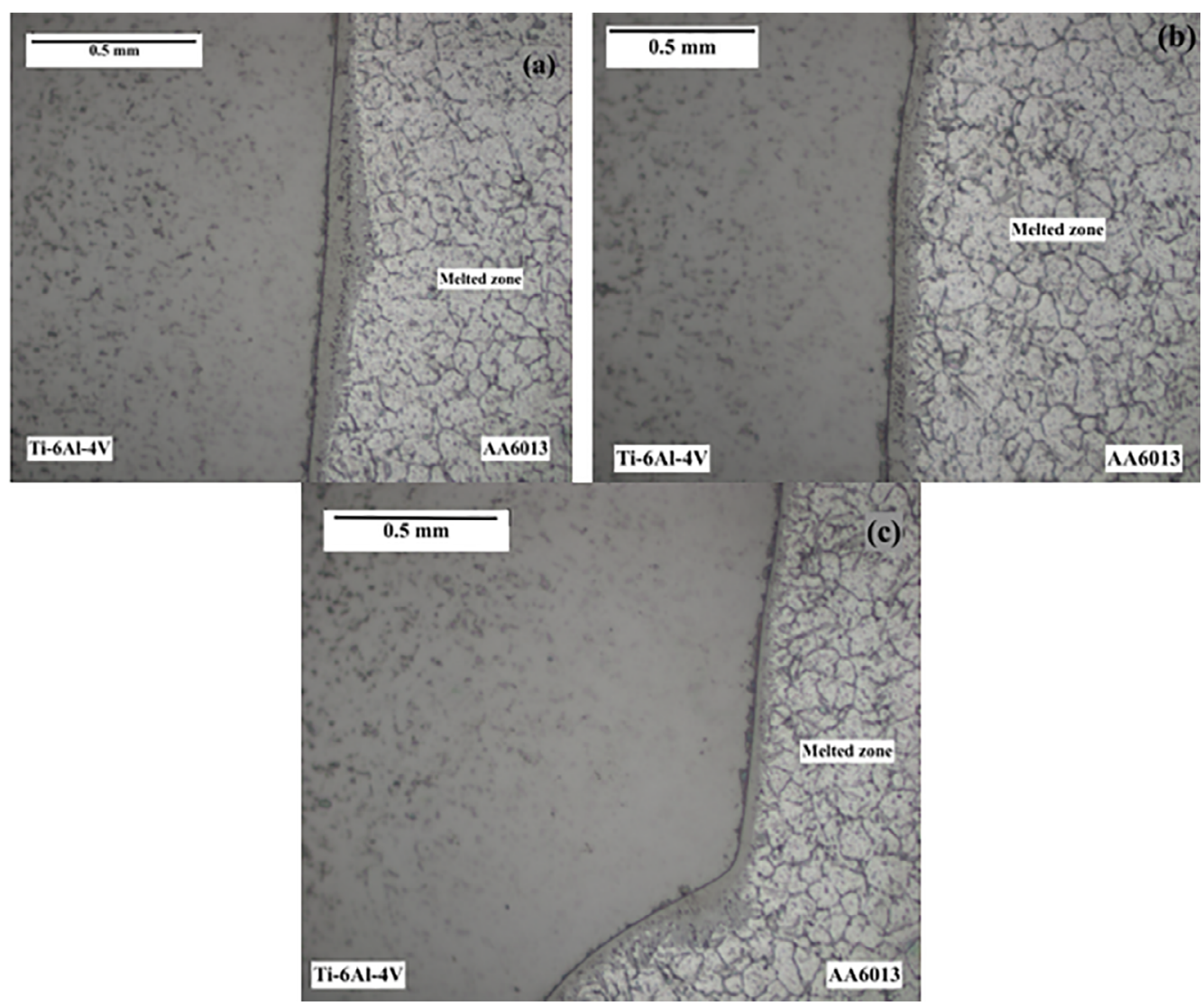

Figure 6. Magnified micrographs of the fusion zone interfacial microstructure, showing the (a) top, (b) middle, and (c) bottom region.

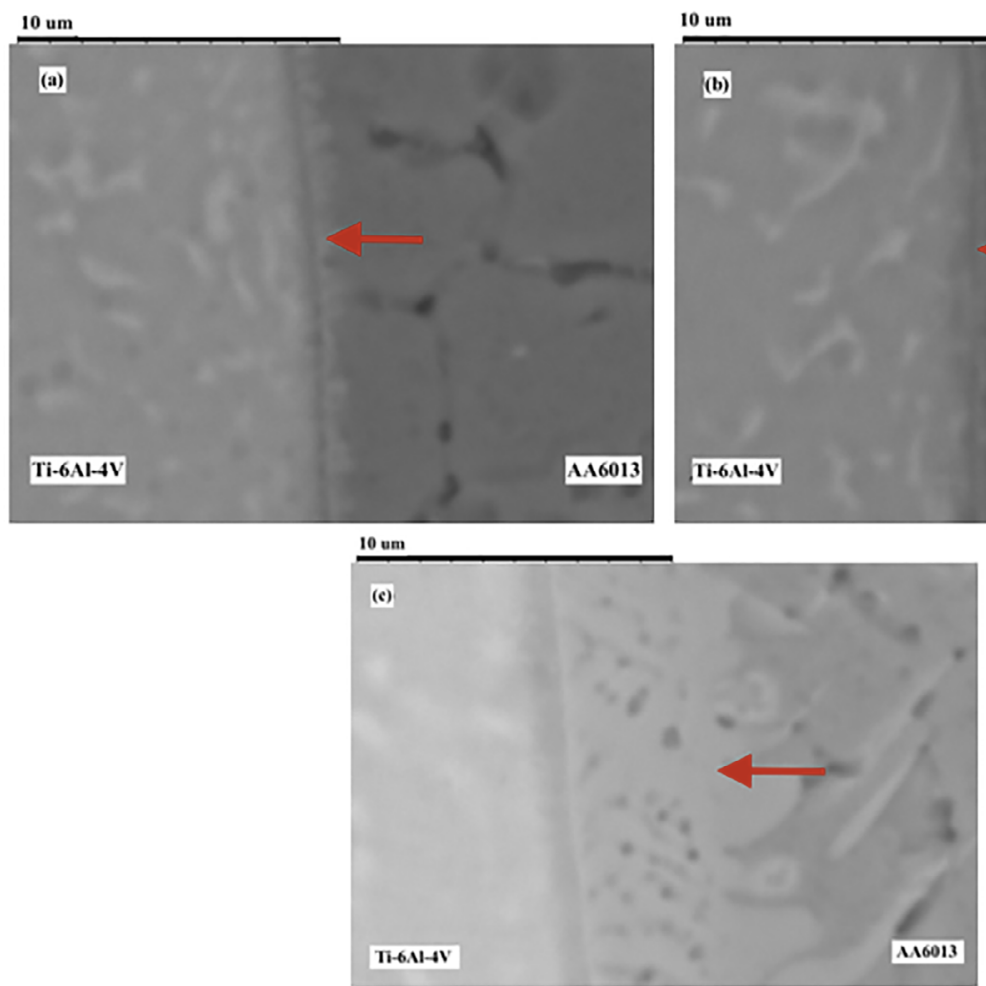

Figure 7. Effect of the silicon film deposited during (a) 1 hour and (b) 2 hours on Ti alloy, comparing with (c) a dissimilar joint without silicon film. 

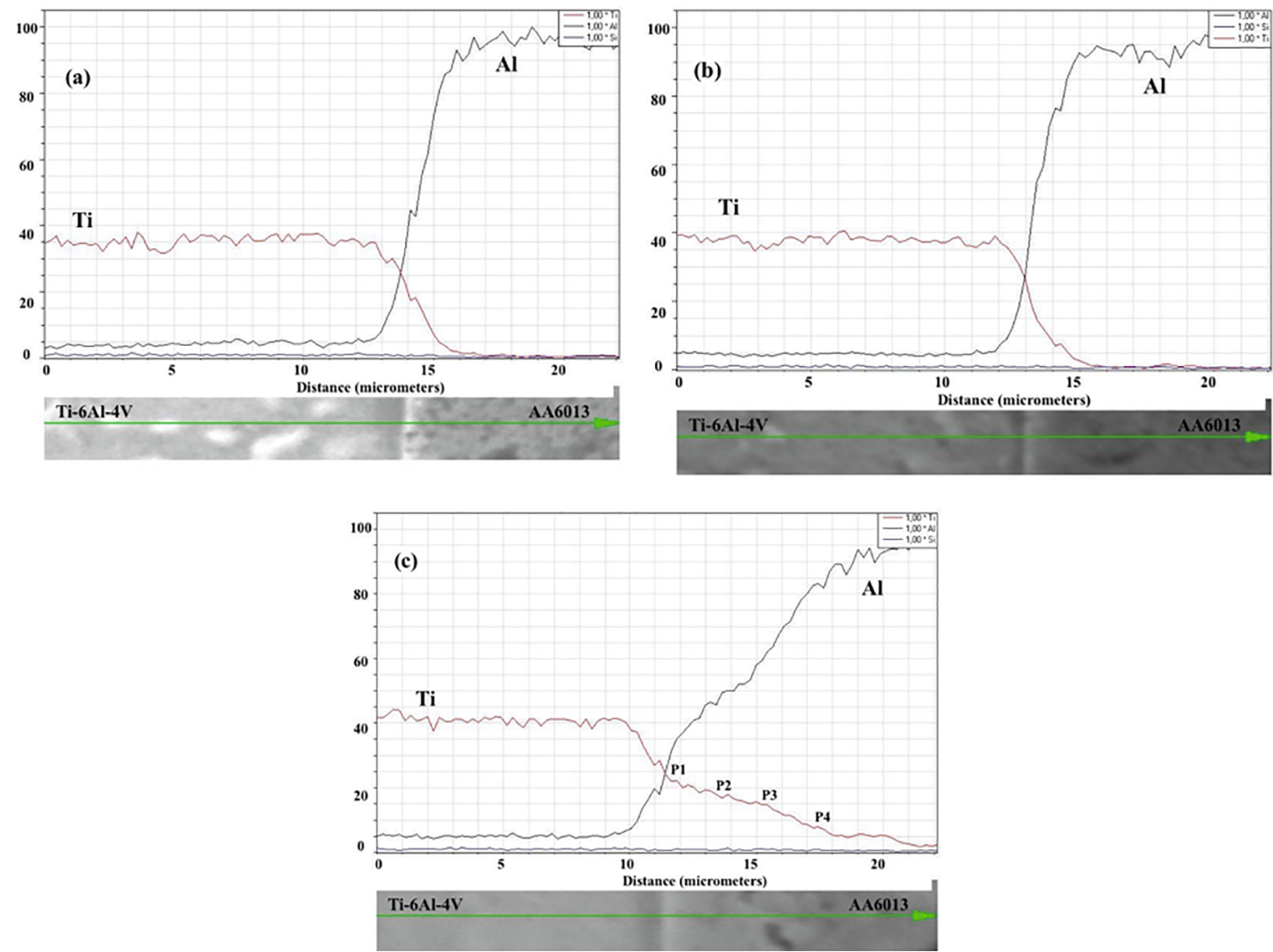

Figure 8. Distribution profile of $\mathrm{Ti}, \mathrm{Al}$ and $\mathrm{Si}$ elements in the joining interface, comparing the effect of the silicon film deposited during (a) 1 hour and (b) 2 hours on Ti alloy, comparing with (c) a dissimilar joint without silicon film.

Table 2. Composition and phase of various regions from Fig.8-c.

\begin{tabular}{cccc}
\hline $\begin{array}{c}\text { Point in } \\
\text { Fig.5-a }\end{array}$ & Ti/at.\% & Al/at.\% & Possible Phase \\
\hline P1 & 47.7 & 52.2 & TiAl \\
P2 & 27.1 & 72.9 & TiAl $_{3}$ \\
P3 & 26.2 & 73.7 & TiAl $_{3}$ \\
P4 & 26.7 & 76.3 & TiAl $_{3}$ \\
\hline
\end{tabular}

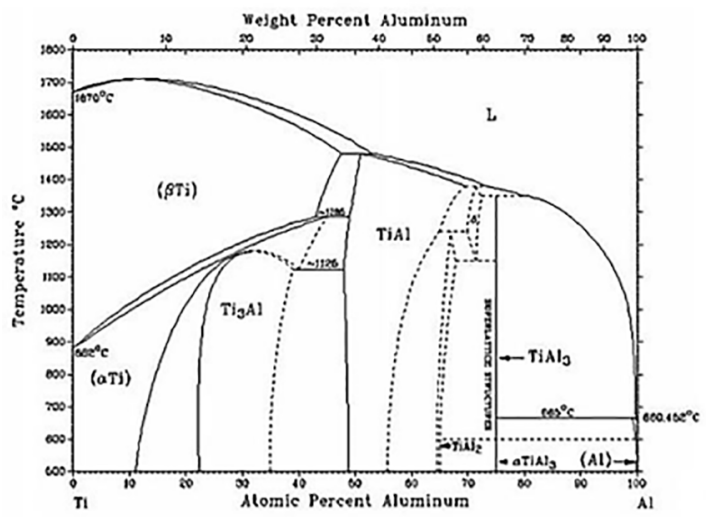

Figure 9. Ti-Al binary phase diagram ${ }^{22}$. titanium and aluminium atoms near the joining interface during the process ${ }^{3}$.

The distribution profiles of the $\mathrm{Ti}, \mathrm{Al}$ and $\mathrm{Si}$ elements at dissimilar joining with silicon film deposited on titanium alloy for 1 and 2 hours are presented in the Figures 8-a and 8-b, respectively, in comparison with a condition without silicon introduction (Figure 8-c). A significant decrease of the titanium diffusion width to aluminium alloy is observed with the introduction silicon in the joining interface. The results are in agreement with the obtained in the microscopy analysis of this region (Figure 7). Moreover, the silicon deposition time influenced the layer thickness formed after joint process. A thin layer is formed with the silicon introduction, in the order of $3 \mu \mathrm{m}$, if compared to joint process without silicon, up to five times thicker. Table 2 summarizes the phase compositions in different points of the curve (Figure 8-c), denoted by P1-P4. Based on the AlSi binary phase diagram (Figure $9^{25}$ ) the possible phases of each some zones are estimated. It is observed a continuous layer between $\mathrm{P} 2$ and $\mathrm{P} 4$ zones, near the interface region and toward aluminium alloy, composed mainly of $\mathrm{TiAl}_{3}$ IMC. In addition, it is observed a thin layer in the transition interface between the alloys composed of TiAl phase. 


\section{Conclusions}

The experimental results reported in this work show the influence of silicon introduction on the dissimilar joining process as to the extension of the compound layer thickness. It was concluded that:

- When the laser beam was positioned near the interface area $(0.3 \mathrm{~mm}$ toward aluminium alloy), the melted aluminium wet the titanium alloy, generating the joining interface with the more restricted compound layer.

- A decrease in the compound layer thickness has been observed with the silicon introduction in the joining interface, reaching the mean value of $3 \mu \mathrm{m}$, i.e., up to five times thinner if compared to joining with no silicon along the joining process.

- The main phases observed in the joining interface were $\mathrm{TiAl}$ and $\mathrm{TiAl}_{3}$. Further studies should associate the influence of compound layer thickness and its composition in the joint fracture behavior.

\section{Acknowledgments}

The author ACO thanks for financial support to FAPESP (process number 2015/18235-0).

\section{References}

1. Vaidya WV, Horstmann M, Ventzke V, Petrovski B, Koçak M, Kocik R, et al. Improving interfacial properties of a laser beam welded dissimilar joint of aluminium AA6056 and titanium Ti6Al4V for aeronautical applications. Journal of Materials Science. 2010;45(22):6242-6254.

2. von der Haar C, Engelbrecht L, Meier O, Ostendorf A, Haferkamp H. Tailored hybrid blank production-New joining concepts using different solders. Journal of Laser Applications. 2008;20(4):224-229.

3. Chen S, Li L, Chen Y, Liu D. Si diffusion behavior during laser welding-brazing of Al alloy and Ti alloy with Al-12Si filler wire. Transactions of Nonferrous Metals Society of China. 2010;20(1):64-70.

4. Tušek J, Kampuš Z, Suban M. Welding of tailored blanks of different materials. Journal of Materials Processing Technology. 2001;119(1-3):180-184.

5. Vaidya WV, Horstmann M, Ventzke V, Petrovski B, Koçak M, Tempus G. Structure-property investigations on a laser beam welded dissimilar joint of aluminium AA6056 and titanium Ti6Al4V for aeronautical applications Part I: Local gradients in microstructure, hardness and strength. Materialwissenschaft und Werkstofftechnik. 2009;40(8):623-633.

6. Liedl G, Kratky A, Mayr M, Saliger A. Laser assisted joining of dissimilar materials. In: Proceedings of IQCMEA-ICFProcessing, Performance and Failure Analysis of Engineering Materials; 2011 Nov 14-17; Luxor, Egypt. p. 22-31.
7. Luo JG, Acoff VL. Interfacial reactions of titanium and aluminum during diffusion welding. Welding Research. 2000;79(9):239s-243s.

8. Morizono Y, Fukuyama T, Matsuda M, Tsurekawa S. LiquidSolid Reactions in Aluminum-Coated Titanium Substrate Fabricated by Using Explosive Energy. Materials Transactions. 2011;52(12):2178-2183.

9. Kimura M, Nakamura S, Kusaka M, Seo K, Fuji A. Mechanical properties of friction welded joint between Ti-6Al-4V alloy and Al-Mg alloy (AA5052). Science and Technology of Welding and Joining. 2005;10(6):666-672.

10. Kattner UR, Lin JC, Chang YA. Thermodynamic Assessment and Calculation of the Ti-Al System. Metallurgical Transactions A. 1992;23(8):2081-2090.

11. Chen Y, Chen S, Li L. Influence of interfacial reaction layer morphologies on crack initiation and propagation in Ti/Al joint by laser welding-brazing. Materials \& Design. 2010;31(1):227233.

12. Naeem $M$, Jessett $R$, Withers $K$. Welding of dissimilar materials with $1 \mathrm{~kW}$ fiber laser. Available from: < http://www.spilasers.com/ wp-content/uploads/2015/12/WEBSITE_WHITE_PAPER_WELDING_OF_DISSIMILAR_MATERIALS_WITH_1KW FIBER_LASER.pdf $>$. Access in: 19/10/2017.

13. Schubert E, Klassen M, Zerner I, Walz C, Sepold G. Lightweight structures produced by laser beam joining for future applications in automobile and aerospace industry. Journal of Materials Processing Technology. 2001;115(1):2-8.

14. Majumdar B, Galun R, Weisheit A, Mordike BL. Formation of a crack-free joint between Ti alloy and Al alloy by using a high-power $\mathrm{CO}_{2}$ laser. Journal of Materials Science. 1997;32(23):6191-6200.

15. Sohn HW, Bong HH, Hong SH. Microstructure and bonding mechanism of Al/Ti bonded joint using Al-10Si-1Mg filler metal. Materials Science and Engineering: A . 2003;355(1-2):231-240.

16. Takemoto $\mathrm{T}$, Okamoto I. Intermetallic compounds formed during brazing of titanium with aluminium filler metals. Journal of Materials Science. 1988;23(4):1301-1308.

17. Kim J, Lee K, Yang S. Wear-corrosion performance of SiDLC coatings on Ti-6Al-4V substrate. Journal of Biomedical Materials Research Part A. 2008;86A(1):41-47.

18. Capote G, Bonetti LF, Santos LV, Corat EJ, Trava-Airoldi JV. Influência da intercamada de silício amorfo na tensão total e na aderência de filmes de DLC em substratos de Ti6Al4V. Revista Brasileira de Aplicações de Vácuo. 2006;25(1):5-10.

19. Gomez-Veja JM, Hozumi A, Saiz E, Tomsia AP, Sugimura H, Tokai O. Bioactive glass-mesoporous sílica coatings on Ti6Al4V through enameling and triblock-copolymer-templated sol-gel processing. Journal of Biomedical Materials Research Part A. 2001;56(3):382-389.

20. Ruska WS. Microelectronic Processing: An Introduction to the Manufacture of Integrated Circuits. New York: McGraw-Hill; 1997.

21. Reinig P, Fenske F, Fuhs W, Selle B. Crystalline silicon films grown by pulsed de magnetron sputtering. Journal of NonCrystalline Solids. 2002;299-302(Pt 1):128-132. 
22. Oliveira AC, Siqueira RHM, Riva R, Lima MSF. One-sided laser beam welding of autogenous T-joints for 6013-T4 aluminium alloy. Materials \& Design. 2015;65:726-736.

23. Oliveira AC, Riva R, Athanazio NMA. Yb:fiber laser joining of Ti-6Al-4V and AA6013 dissimilar metals. In: Proceeding of Lasers in Manufacturing Conference; 2015 Jun 22-25; Munich, Germany.
24. Song Z, Nakata $\mathrm{K}, \mathrm{Wu} \mathrm{A}$, Liao J. Interfacial microstructure and mechanical property of Ti6A14V/A6061 dissimilar joint by direct laser brazing without filler metal and groove. Materials Science and Engineering: A. 2013;560:111-120.

25. Cao R, Sun JH, Chen JH. Mechanisms of joining aluminium A6061-T6 and titanium Ti-6Al-4V alloys by cold metal transfer technology. Science and Technology of Welding and Joining. 2013;18(5):425-433. 